\title{
Substituting abacavir for hyperlipidemia-associated protease inhibitors in HAART regimens improves fasting lipid profiles, maintains virologic suppression, and simplifies treatment
} Philip H Keiser*1, Michael G Sension², Edwin DeJesus ${ }^{3}$, Allan Rodriguez ${ }^{4}$, Jeffrey F Olliffe ${ }^{5}$, Vanessa C Williams ${ }^{6}$, John H Wakeford ${ }^{6}$, Jerry W Snidow ${ }^{6}$, Anne D Shachoy-Clark ${ }^{6}$, Julie W Fleming ${ }^{6}$, Gary E Pakes ${ }^{6}$, Jaime E Hernandez ${ }^{6}$ and for the ESS40003 Study Team

Address: ${ }^{1}$ University of Texas Southwestern Medical Center, Dallas, Texas, USA, ${ }^{2}$ North Broward Hospital, Ft. Lauderdale, Florida, USA, ${ }^{3}$ IDC Research Initiative, Altamonte Springs, Florida, USA, ${ }^{4}$ University of Miami, Miami, Florida, USA, ${ }^{5}$ Swedish Hospital, Seattle, Washington, USA and ${ }^{6}$ GlaxoSmithKline, Research Triangle Park, North Carolina, USA

Email: Philip H Keiser* - Philip.Keiser@utsouthwestern.edu; Michael G Sension - msension@nbhd.org;

Edwin DeJesus - EdwinDeJesusMD@aol.com; Allan Rodriguez - arodriguez2@med.miami.edu; Jeffrey F Olliffe - jolliffe@u.washington.edu; Vanessa C Williams - vanessa.c.williams@gsk.com; John H Wakeford - john.h.wakeford@gsk.com; Jerry W Snidow - jerry.w.snidow@gsk.com; Anne D Shachoy-Clark - anne.d.shachoy-clark@gsk.com; Julie W Fleming - julie.w.fleming@gsk.com; Gary E Pakes - gary.e.pakes@gsk.com; Jaime E Hernandez - jaime.e.hernandez@gsk.com; for the ESS40003 Study Team - Philip.Keiser@utsouthwestern.edu

* Corresponding author

Published: 12 January 2005

BMC Infectious Diseases 2005, 5:2 doi:10.1186/147/-2334-5-2
Received: 02 March 2004

Accepted: 12 January 2005

This article is available from: http://www.biomedcentral.com/I47I-2334/5/2

(c) 2005 Keiser et al; licensee BioMed Central Ltd.

This is an Open Access article distributed under the terms of the Creative Commons Attribution License (http://creativecommons.org/licenses/by/2.0), which permits unrestricted use, distribution, and reproduction in any medium, provided the original work is properly cited.

\begin{abstract}
Background: Hyperlipidemia secondary to protease inhibitors (PI) may abate by switching to antiHIV medications without lipid effects.

Method: An open-label, randomized pilot study compared changes in fasting lipids and HIV-I RNA in 104 HIV-infected adults with Pl-associated hyperlipidemia (fasting serum total cholesterol $>200$ $\mathrm{mg} / \mathrm{dL}$ ) who were randomized either to a regimen in which their PI was replaced by abacavir 300 $\mathrm{mg}$ twice daily $(n=52)$ or a regimen in which their PI was continued $(n=52)$ for 28 weeks. All patients had undetectable viral loads (HIV-I RNA $<50$ copies $/ \mathrm{mL}$ ) at baseline and were naïve to abacavir and non-nucleoside reverse transcriptase inhibitors.

Results: At baseline, the mean total cholesterol was $243 \mathrm{mg} / \mathrm{dL}$, low density lipoprotein (LDL)cholesterol $149 \mathrm{mg} / \mathrm{dL}$, high density lipoprotein (HDL)-cholesterol $4 \mathrm{l} \mathrm{mg} / \mathrm{dL}$, and triglycerides 310 $\mathrm{mg} / \mathrm{dL}$. Mean CD4+ cell counts were $55 \mathrm{I}$ and $53 \mathrm{I}$ cells $/ \mathrm{mm}^{3}$ in the abacavir-switch and PIcontinuation arms, respectively. At week 28 , the abacavir-switch arm had significantly greater least square mean reduction from baseline in total cholesterol $(-42 \mathrm{vs}-10 \mathrm{mg} / \mathrm{dL}, P<0.00 \mathrm{I})$, LDLcholesterol (-14 vs $+5 \mathrm{mg} / \mathrm{dL}, P=0.016)$, and triglycerides $(-134 \mathrm{vs}-36 \mathrm{mg} / \mathrm{dL}, P=0.019)$ than the $\mathrm{Pl}$-continuation arm, with no differences in HDL-cholesterol $(+0.2 \mathrm{vs}+1.3 \mathrm{mg} / \mathrm{dL}, P=0.583)$. A higher proportion of patients in the abacavir-switch arm had decreases in protocol-defined total cholesterol and triglyceride toxicity grades, whereas a smaller proportion had increases in these toxicity grades. At week 28 , an intent-to treat: missing = failure analysis showed that the abacavirswitch and PI-continuation arms did not differ significantly with respect to proportion of patients maintaining HIV-I RNA $<400$ or $<50$ copies $/ \mathrm{mL}$ or adjusted mean change from baseline in CD4+
\end{abstract}


cell count. Two possible abacavir-related hypersensitivity reactions were reported. No significant changes in glucose, insulin, insulin resistance, C-peptide, or waist-to-hip ratios were observed in either treatment arm, nor were differences in these parameters noted between treatments.

Conclusion: In hyperlipidemic, antiretroviral-experienced patients with HIV-I RNA levels $<50$ copies $/ \mathrm{mL}$ and CD4+ cell counts $>500$ cells $/ \mathrm{mm}^{3}$, substituting abacavir for hyperlipidemiaassociated Pls in combination antiretroviral regimens improves lipid profiles and maintains virologic suppression over a 28-week period, and it simplifies treatment.

\section{Background}

Protease inhibitors (PIs) used as components of highly active antiretroviral therapy (HAART) have been well documented to reduce both the morbidity and mortality associated with HIV infection [1,2]. However, many PI-based HAART regimens incur treatment-limiting side effects, interactions with concomitant medications, high daily pill burdens, and dietary and/or fluid requirements, making adherence to treatment a challenge [3]. Even more problematic from a long-term treatment perspective are the metabolic adverse effects, such as hyperlipidemia, insulin resistance, and lipodystrophy, which along with HIV infection itself, may constitute major risk factors for the development of coronary artery disease (CAD) [4].

The incidence of hyperlipidemia varies among PIs. The Swiss HIV Cohort Study showed that over 470 days, HIVinfected patients experienced a mean increase in total cholesterol of $77 \mathrm{mg} / \mathrm{dL}$ with ritonavir $(n=46), 46 \mathrm{mg} / \mathrm{dL}$ with nelfinavir $(n=21), 31 \mathrm{mg} / \mathrm{dL}$ with indinavir $(n=26)$, and $4 \mathrm{mg} / \mathrm{dL}$ with non-PI-containing antiretroviral regimens $(n=28)$ [5]. At the end of the study, total cholesterol exceeded $240 \mathrm{mg} / \mathrm{dL}$ in $44 \%$ of the ritonavir group, 35\% of the indinavir group, $33 \%$ of the nelfinavir group, and $14 \%$ of the non-PI group. Other research has shown that some of the more recently developed PIs, including fosamprenavir and atazanavir, have a low likelihood of causing significant lipid elevation or adversely affecting the total cholesterol: high density lipoprotein (HDL) cholesterol ratio [6-8]. Although HIV infection itself is associated with above-normal triglyceride levels due to diseaserelated reduction in triglyceride clearance and increase in de-novo hepatic lipogenesis [9], some PIs exacerbate this lipid elevation by down-regulating low density lipoprotein (LDL)-receptor expression [10], interfering with the proteasome-mediated degradation of activated nuclear sterol regulatory element-binding protein-1 [11], and reducing triglyceride clearance further [12].

Because PIs have been available for less than a decade, it may be too early to confirm an association between PI usage and a more rapid onset of CAD. Epidemiological studies to date have reported varying findings regarding a PI-CAD link [13-15]. Until questions about such a possible link are resolved, it appears prudent to treat HIV- infected patients who have CAD risk factors with combinations of antiretroviral agents that produce maximal virologic suppression with the fewest lipid-elevating effects and metabolic adverse events.

Unlike most PIs, the nucleoside reverse transcriptase inhibitor (NRTI) abacavir is administered as just one tablet twice daily with no requirements regarding extra hydration or dosing with or without meals [16]. Abacavir is unlikely to be involved in drug interactions because it does not affect CYP3A4 drug metabolism, its use does not affect lipids or metabolic parameters, and it does not cause lipodystrophy [16]. These features of abacavir have prompted its use in substituting for components of HAART regimens in order to simplify treatment and to obviate the risk of drug interactions, fat maldistribution, and metabolic complications [17]. HAART regimens containing abacavir have been shown in direct comparative trials in HIV-infected patients with a baseline viral load $<100,000$ copies/mL to be as effective as nelfinavir-and indinavir-containing HAART in suppressing viral load and increasing CD4+ cell counts without inducing hyperlipidemia, insulin resistance, or central adiposity [18-21]. In patients with a baseline viral load $\geq 100,000$ copies/mL, abacavir in combination with lamivudine and zidovudine has been shown to suppress viral load and increase CD4+ cell counts as well as nelfinavir-containing HAART [20], and was as effective as indinavir-containing HAART in one trial [18] but not in another [21]. In view of these findings, we conducted a 28-week, open-label pilot study (ESS40003) to compare the changes in PI-associated hyperlipidemia (fasting serum total cholesterol $>200 \mathrm{mg} /$ $\mathrm{dL}$ ) in treatment-experienced HIV-infected patients with HIV-1 RNA $<50$ copies/mL who either substituted abacavir for the PI component in their regimen or continued the same PI-containing regimen.

\section{Methods \\ Patient selection}

Male and non-pregnant, non-lactating female outpatients were eligible for study enrollment if they were at least 18 years of age; had HIV-1 infection (documented by HIV-1 antibody enzyme-linked immunosorbent assay and confirmed by Western blot test of HIV-1 antibody, or positive HIV-1 blood culture, positive HIV serum antigen, or 
plasma viremia); had fasting serum total cholesterol $>200$ $\mathrm{mg} / \mathrm{dL}$; were stabilized on a well-tolerated PI-containing antiretroviral regimen for $>3$ months (either 2 NRTIs +1 PI, or 2 NRTIs + 2 PIs if one PI was ritonavir); were naïve to abacavir and all non-nucleoside reverse transcriptase inhibitors (NNRTIs); and if their two most recently reported consecutive plasma HIV-1 RNA values were $<400$ copies/mL prior to screening and HIV-1 RNA was $<50$ copies/mL at screening. CD4+ cell counts could be of any magnitude. Patients were also eligible if their HAART regimen had changed due to intolerance (one drug substitution, such as a PI for another PI and/or an NRTI for another NRTI) >12 weeks prior to study start; or if their initial HAART regimen consisted of 2 NRTIs followed within 1 year by the addition of a PI. Patients were excluded from the study if they had genetically-related lipid disorders (familial lipoprotein lipase deficiency, apoprotein CII deficiency, type 3 hyperlipoproteinemia, hypercholesterolemia, hypertriglyceridemia, or combined hyperlipidemia); took a hypolipidemic or antidiabetic drug within 30 days of screening; had an AIDS-defining opportunistic infection or disease within 30 days of study entry; had a history of angina, anginal symptoms, and/or myocardial infarction; were substance abusers; or had a malabsorption syndrome that could interfere with absorption of the study medications. Patients provided written informed consent to participate in the study.

\section{Study design and treatment}

This Phase IV, parallel group, active control, randomized, open-label, multicenter trial was conducted between November 1999 and November 2001 at 44 outpatient sites in the United States. An Institutional Review Board approved the study protocol at each site. To determine study eligibility, study candidates underwent a medical history, physical examination, CDC classification, clinical chemistry, hematology, and $\beta$-human chorionic gonadotropin test (women of childbearing age only) at the screening visit within 14 days pre-study. Patients meeting entry criteria at screening were randomized to either continued therapy with their current PI-containing antiretroviral regimen or to the same regimen with abacavir (300 mg twice daily) substituted for the PI(s). Abacavir was supplied as 300-mg tablets of Ziagen ${ }^{\circledR}$ (GlaxoSmithKline, Research Triangle Park, North Carolina). In the abacavirswitch arm, patients received both abacavir and the hyperlipidemia-associated PI with their usual two-NRTI background combination for the first 4 weeks, after which the PI component of the regimen was discontinued. Coadministration of abacavir and the PI was done during the first 4 weeks to make sure that there was virologic coverage in case a patient developed a suspected abacavirrelated hypersensitivity reaction, which would have necessitated stopping abacavir. Blood was sampled for lipid, viral load, and laboratory value measurements from fasted patients at baseline, and at weeks 4, 8, 12, 20, and 28. Patients who experienced HIV-1 RNA breakthrough (defined as HIV-1 RNA values between 50 and 1000 copies/mL by Roche Amplicor Ultrasensitive Assay) during the study period could receive intensification with efavirenz $600 \mathrm{mg}$ once daily.

\section{Assessment of lipids}

A complete fasting lipid panel was obtained from blood samples at baseline and at weeks $4,8,12,20$, and 28 to allow measurement of the primary study endpoint (change from baseline in fasting serum total cholesterol) and secondary study endpoints (change from baseline in LDL-cholesterol, very low density lipoprotein (VLDL)cholesterol, high density lipoprotein (HDL)-cholesterol, and triglycerides). Apolipoproteins $\mathrm{B}$ and $\mathrm{E}$, free fatty acids, and LDL subfractions were measured at baseline and week 28. Direct LDL-cholesterol was measured in all patients at baseline, week 4, and week 28, as well as any treatment visit at which time a fasting triglyceride $>400$ $\mathrm{mg} / \mathrm{dL}$ was observed.

Fasting serum total cholesterol and triglyceride levels were measured enzymatically by using cholesterol/HP reagent (Roche Diagnostics, Indianapolis, Indiana) and triglyceride reagent (GPO-Trender) (Roche Diagnostics, Ibid). HDL-cholesterol was measured enzymatically in the supernatant formed following centrifugation of serum mixed with a polyanion dextran sulfate/divalent magnesium solution (Roche Diagnostics, Ibid). LDL- and VLDLcholesterol were estimated by the Friedewald equation [22]. Direct LDL-cholesterol was measured by a nonionic detergent method using alpha-cyclodextrin/4-aminoantipyrin (Roche Diagnostics, Ibid.). Apolipoprotein B was measured using the apolipoprotein B antigen-antibody reaction method employing the Beckman IMMAGE Immunochemistry System (Beckman Instrument, Brea, California), and apolipoprotein E by a phosphate buffer/ anti-human apolipoprotein E method employing a Wako Apolipoprotein Calibrator (WAKO Chemicals, Richmond, Virginia). LDL subfractions were measured by electrophoresis (Pacific Biometrics, Seattle, Washington) [23], and non-esterified free fatty acids were measured by the WAKO enzymatic colorimetic method (WAKO Chemicals, Ibid.).

Four protocol-defined toxicity grades for hyperlipidemia were assigned during the study for serum cholesterol (Grade 1 for values $>1-1.3$ times the upper limit of normal [ULN], Grade 2 for $>1.3-1.6$ times the ULN, Grade 3 for $>1.6-2$ times the ULN; and Grade 4 for $>2$ times the ULN) and serum triglycerides (Grade 1 for ULN-399 mg/ $\mathrm{dL}$, Grade 2 for $400-750 \mathrm{mg} / \mathrm{dL}$, Grade 3 for $751-1200$ $\mathrm{mg} / \mathrm{dL}$, and Grade 4 for $>1200 \mathrm{mg} / \mathrm{dL}$ ). 


\section{Efficacy assessment}

Changes in HIV-1 RNA levels and CD4+ cell counts were secondary endpoints in this study. Plasma HIV-1 RNA levels were measured in blood samples at screening and at all study visits using both the Roche AMPLICOR PCR Standard 1.0 assay (lower limit of quantitation [LLOQ] 400 copies/mL) and the Roche PCR assay Amplicor HIV-1 MONITOR UltraSensitive Version 1.0 (LLOQ 50 copies/ $\mathrm{mL}$ ) (both assays from Roche Diagnostics, Branchburg, New Jersey). Virologic failure was defined as HIV-1 RNA $>1000$ copies/mL on two occasions at least 1 week apart. CD4+ cell counts were determined by flow cytometry at baseline, and at weeks 4, 12, 20, and 28 .

\section{Safety assessment}

Frequency and severity of all clinical and laboratory adverse experiences were assessed at each visit. A cardiovascular disease risk factor assessment was conducted at baseline only. Body mass index (BMI) and waist-to-hip ratio (WHR) were measured at baseline and at weeks 4,8 , 12,20 and 28. Three types of waist measurements were conducted: mid, minimal, and umbilicus. Insulin resistance measures (C-peptide and fasting insulin to glucose ratio) were assessed at baseline and at weeks 4, 8, 12, 20, and 28 . Leptin and lactate were measured at baseline and week 28.

Diagnosis of possible abacavir-related hypersensitivity reaction was to be considered if the following multi-organ signs and symptoms appeared in a patient following initiation of abacavir: fever, rash, gastrointestinal symptoms (nausea, vomiting, diarrhea, or abdominal pain), lethargy, or malaise with or without concomitant respiratory symptoms (dyspnea, sore throat, cough), musculoskeletal symptoms (myalgia, myolysis, arthralgia), headache, paresthesia, and edema. No rechallenge of abacavir was permitted in patients developing this syndrome. The definition and usual clinical presentation of abacavirrelated hypersensitivity has been defined previously $[24,25]$.

\section{Adherence and health outcomes assessments}

Adherence was assessed by the Patient Medication Adherence Questionnaire-7 (PMAQ-7) [26]. The PMAQ-7 is a self-reported measure of adherence that patients completed at baseline and at weeks 4, 8, 12, 20, and 28 (or upon permanent discontinuation due to virologic failure or toxicity). In the PMAQ-7, patients were asked to indicate the number of doses of each medication they took during each of the previous 7 days. An overall regimen adherence rate was calculated at each week as the proportion of doses actually taken relative to the number of doses prescribed summed across each medication within the regimen. The PMAQ-7 also measured barriers and motivators to adherence.
Health-related quality of life (QOL) was evaluated using the Medical Outcomes Study 36-item Short Form Health Survey (SF-36) [27], which patients completed at baseline and at study weeks 12 and 28. Healthcare resource utilization (total health care visits, emergency room visits, intensive care hospitalizations [nights], general ward hospitalizations [nights], outpatient clinic visits, home care visits, and long-term care visits [nights]) was assessed at weeks 4, 8, 12, 20 and 28 .

\section{Statistical analysis}

A sample size of 80 patients per treatment arm was deemed necessary for $80 \%$ power to detect a difference of $20 \mathrm{mg} / \mathrm{dL}$ in fasting total cholesterol between groups using a two-group $t$-test with a two-sided significance level of 0.05 , assuming a dropout rate of $20 \%$. This sample size calculation is based on data from NZTA4002, in which the standard deviation of total cholesterol in the nelfinavir/zidovudine/lamivudine group at baseline was 39.5 $\mathrm{mg} / \mathrm{dL}$.

The primary efficacy population was the intent-to-treat (ITT) population, which consisted of all patients who were randomized into the study. The safety population consisted of all randomized patients who received at least one dose of study drug. Analysis of covariance (ANCOVA) was used to compare the least squares means (LSM) of the two treatment groups. The LSM represented the mean value adjusted for the average value of the covariate from both treatment groups. LSMs of change from baseline in serum lipids (total, LDL, VLDL, and HDL-cholesterol, LDL subfractions, triglycerides, free fatty acids), apolipoprotein B, apolipoprotein E, leptin, C-peptide, glucose, insulin, and lactate were reported. The ANCOVA model included terms for treatment group, baseline value of the variable of interest, PI strata and gender.

Two types of analyses were performed with HIV-1 RNA data: the ITT: observed analysis and the ITT missing equals failure analysis (ITT: $\mathrm{M}=\mathrm{F}$ ). In the ITT: observed analysis, only available assessments were used (no imputation for missing values), regardless of whether the patient was still receiving their original therapy. In the ITT: $\mathrm{M}=\mathrm{F}$ analysis, all missing values were considered as failure. Proportions of patients with HIV-1 RNA $<400$ copies/mL and $<50$ copies/mL were compared between treatment groups with a $95 \%$ confidence interval (CI) on the difference between proportions.

Differences in domain scores to the SF-36 and the PMAQ7 were compared using the Wilcoxon rank sum test. Differences between treatment arms in the incidence of treatment-related adverse events by body system were evaluated by Fisher's Exact test. A $P$ value of 0.05 was considered statistically significant. 


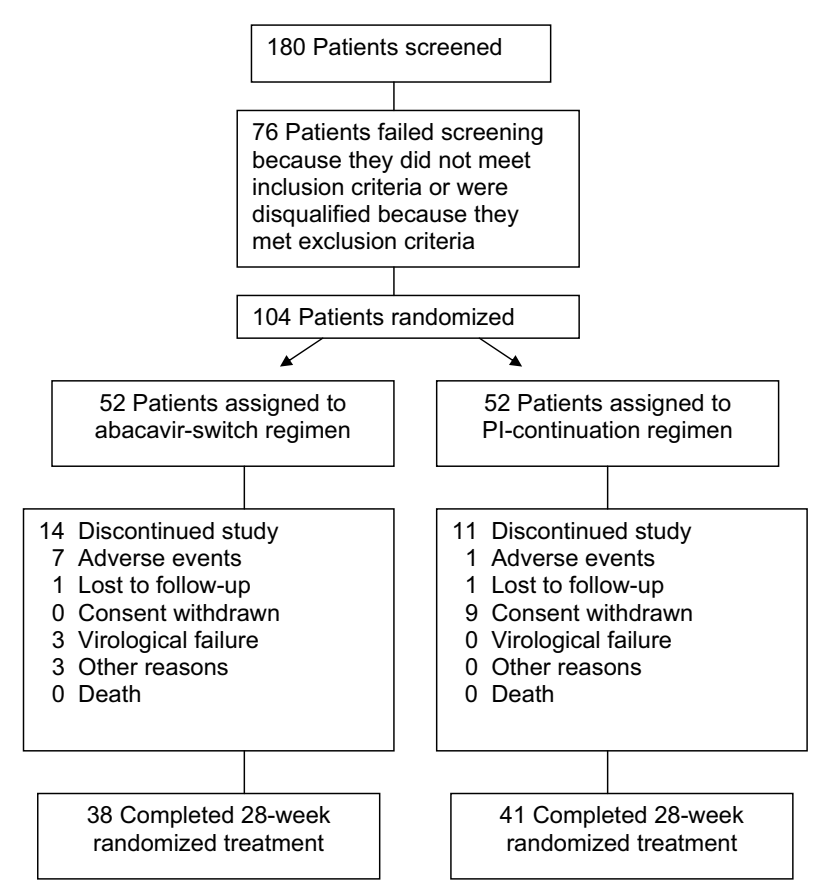

Figure I

Profile of patient enrollment and discontinuations through 28 weeks of treatment.

\section{Results}

\section{Patient characteristics and disposition}

Of 104 patients enrolled in the study, 52 were randomized to the abacavir-switch arm and 52 to the PI-continuation arm (Figure 1). Most of the patients were males (89\%), and the median age was 42 years (Table 1$)$. The study population was ethnically diverse; approximately one-half were Caucasian, one-quarter African American, and one-quarter Hispanic. Mean CD4+ cell counts were 551 and 531 cells $/ \mathrm{mm}^{3}$ in the abacavir-switch and PI-continuation arms, respectively. About two-thirds of the patients were HIV Category A. The abacavir-switch and PIcontinuation arms were well matched with respect to mean baseline HIV-1 RNA levels (1.727 vs $1.699 \log _{10}$ copies/mL, $P=0.062$ ), total cholesterol (244 vs $241 \mathrm{mg} /$ dL), LDL-cholesterol (149 vs 149 mg/dL), VLDL-cholesterol (68 vs $56 \mathrm{mg} / \mathrm{dL}$ ), HDL-cholesterol (39 vs $42 \mathrm{mg} /$ $\mathrm{dL}$ ), triglycerides (340 vs $280 \mathrm{mg} / \mathrm{dL})$, CAD risk factors (Table 1), and specific PI used immediately pre-study (>80\% receiving either nelfinavir or indinavir). There were no significant differences between treatment arms with respect to baseline BMI, waist-to-hip ratios or insulin resistance. During treatment, the background NRTIs used in the abacavir-switch and PI-continuation arms were similar and included most commonly the lamivudine 150 $\mathrm{mg} /$ zidovudine $300 \mathrm{mg}$ combination tablet (Combivir ${ }^{\circledR}$ [GlaxoSmithKline, Ibid.], 52\% vs $47 \%)$, stavudine $(36 \%$ vs $42 \%$ ), lamivudine (32\% vs $40 \%$ ), and zidovudine ( $6 \%$ vs $2 \%$ ).

A similar number of patients withdrew prematurely from the study for the reasons delineated in Table 1. Comparatively more patients withdrew due to adverse events in the abacavir-switch arm (7/52 vs 1/52) and due to consent withdrawn in the PI-continuation arm ( 0 vs $9 / 52$ [all withdrawals occurred after the patients learned they were not receiving abacavir]). The difference between the two treatment arms regarding number of premature withdrawals due to the sum of adverse events plus virologic failure was not statistically significant $(P=0.144)$. No patient required efavirenz intensification of their treatment regimen.

\section{Changes in lipids}

In the ITT analysis, the abacavir-switch arm experienced greater reductions in total cholesterol (Figure 2) and LDLcholesterol (Figure 3) than the PI-continuation arm over the entire study period, with differences between treatment arms being statistically significant from week 8 onward. At week 28, patients in the abacavir-switch arm had a significantly greater LSM decrease from baseline in total cholesterol (-42 vs $-10 \mathrm{mg} / \mathrm{dL} ; P<0.001)$, LDL-cholesterol $(-14 \mathrm{vs}+5 \mathrm{mg} / \mathrm{dL} ; P=0.016)$, LDL direct-cholesterol $(-15 \mathrm{vs}+1 \mathrm{mg} / \mathrm{dL} ; P=0.028)$, VLDL-cholesterol $(-27$ vs $-7 \mathrm{mg} / \mathrm{dL} ; P=0.019)$, triglycerides $(-134 \mathrm{vs}-36 \mathrm{mg} / \mathrm{dL}$; $P=0.019)$, apolipoprotein B (-23 vs $-11 \mathrm{mg} / \mathrm{dL} ; P=$ $0.031)$, and apolipoprotein E ( $-2 \mathrm{vs}-1 \mathrm{mg} / \mathrm{dL} ; P=0.021)$ versus the PI-continuation arm. Over the study period, no significant differences were observed between the abacavir-switch or PI-continuation arms with respect to LDL subfractions (particle size A and major class) or HDLcholesterol (LSM change from baseline at week $28,+0.2$ vs $+1.3 \mathrm{mg} / \mathrm{dL}, P=0.583$; LSM at week $28,40 \mathrm{vs} 41 \mathrm{mg} / \mathrm{dL})$. The abacavir-switch arm showed a trend for greater LSM reduction from baseline in free fatty acids (-0.3 vs -0.2 $\mathrm{mEq} / \mathrm{L} ; P=0.052)$.

The LSM value for total cholesterol was below the National Cholesterol Education Program Adult Treatment Panel III (NCEP ATP III) goal value $(<200 \mathrm{mg} / \mathrm{dL}$ ) in the abacavir-switch arm (198 mg/dL); however, it remained above this value in the PI-continuation arm $(230 \mathrm{mg} / \mathrm{dL})$. The LSM LDL-cholesterol level at week 28 was $133 \mathrm{mg} / \mathrm{dL}$ in the abacavir-switch arm and $153 \mathrm{mg} / \mathrm{dL}$ in the PI-continuation arm $(P=0.016)$. A higher proportion of patients in the abacavir-switch arm had shifts to lower toxicity grades as compared to the PI-continuation arm, whereas a lower proportion in the abacavir-switch arm had shifts from baseline in cholesterol to more severe toxicity grades (Figure 4) 
Table I: Characteristics and disposition of the study patients (intent-to-treat population)

\begin{tabular}{|c|c|c|c|}
\hline Characteristic & $\begin{array}{l}\text { Abacavir-switch arm } \\
(N=52)\end{array}$ & $\begin{array}{l}\text { PI-continuation arm } \\
(\mathrm{N}=52)\end{array}$ & $\begin{array}{l}\text { Total study population } \\
(\mathrm{N}=104)\end{array}$ \\
\hline \multicolumn{4}{|l|}{ Age, y } \\
\hline Median (range) & $43(23-64)$ & $42(25-62)$ & $42(23-64)$ \\
\hline \multicolumn{4}{|l|}{ Sex, No. (\%) } \\
\hline Male & $46(88)$ & $47(90)$ & $93(89)$ \\
\hline Female & $6(12)$ & $5(10)$ & II (II) \\
\hline \multicolumn{4}{|l|}{ Race, No. (\%) } \\
\hline Caucasian & $26(50)$ & $28(54)$ & $54(52)$ \\
\hline African American & $16(31)$ & II (2I) & $27(26)$ \\
\hline Hispanic & $10(19)$ & $13(25)$ & $23(22)$ \\
\hline Mean HIV-I RNA, $\log _{10}$ copies/mL (SD) & $1.73(0.16)$ & $1.69(0.04)$ & $1.71(0.06)$ \\
\hline Mean CD4+ cell count, cells $/ \mathrm{mm}^{3}(\mathrm{SD})$ & $551(226)$ & $531(233)$ & $54 \mid(229)$ \\
\hline Mean weight, kg (SD) & $79.3(16.8)$ & $80.4(16.6)$ & $79.8(16.7)$ \\
\hline Mean BMI, kg/cm² (SD) & $25.9(4.5)$ & $26.4(4.9)$ & $26.1(4.7)$ \\
\hline Mean waist-to-hip ratio & $0.94(0.06)$ & $0.93(0.07)$ & $0.94(0.06)$ \\
\hline \multicolumn{4}{|l|}{ CDC Class, n (\%) } \\
\hline Category A & $33(63)$ & $34(65)$ & $67(64)$ \\
\hline Category B & $10(19)$ & II (2I) & $21(20)$ \\
\hline Category C & $9(17)$ & $7(13)$ & $16(15)$ \\
\hline Mean (SD) total cholesterol, $\mathrm{mg} / \mathrm{dL}$ & $244(45)$ & $24 \mid(44)$ & \\
\hline Mean (SD) LDL cholesterol, mg/dL & $149(34)$ & $149(30)$ & \\
\hline Mean (SD) HDL cholesterol, mg/dL & $39(15)$ & $42(14)$ & \\
\hline Mean (SD) triglycerides, $\mathrm{mg} / \mathrm{dL}$ & $340(213)$ & $280(282)$ & \\
\hline Coronary artery disease risk factors, $\mathrm{n}(\%)^{*}$ & $34(65)$ & $26(50)$ & $60(58)$ \\
\hline Age & $18(35)$ & $12(23)$ & $30(29)$ \\
\hline Family history & $4(8)$ & $4(8)$ & $8(8)$ \\
\hline Cigarette smoking & $19(37)$ & $13(25)$ & $32(3 I)$ \\
\hline Hypertension & $5(10)$ & $8(15)$ & $13(13)$ \\
\hline Low HDL & $10(19)$ & $4(8)$ & $14(13)$ \\
\hline Diabetes mellitus & $3(6)$ & 0 & $3(3)$ \\
\hline \multicolumn{4}{|c|}{ Antiretroviral medications taken prior to screening, $\mathrm{n}(\%)$} \\
\hline Any & $28(56)$ & $20(44)$ & $48(46)$ \\
\hline \multicolumn{4}{|l|}{ NRTIs } \\
\hline Zidovudine & $16(32)$ & $9(20)$ & $25(24)$ \\
\hline Lamivudine & $12(24)$ & $8(18)$ & $20(19)$ \\
\hline Stavudine & $5(10)$ & $2(4)$ & $7(7)$ \\
\hline Didanosine & $7(14)$ & 0 & $7(7)$ \\
\hline Zalcitabine & $3(6)$ & 0 & $3(3)$ \\
\hline \multicolumn{4}{|l|}{ NNRTIs } \\
\hline Efavirenz & I (2) & 0 & \\
\hline \multicolumn{4}{|l|}{ Pls } \\
\hline Indinavir & II (22) & $8(18)$ & $19(18)$ \\
\hline Nelfinavir & $4(8)$ & $2(4)$ & $6(6)$ \\
\hline Ritonavir & $2(4)$ & I (2) & $3(3)$ \\
\hline Saquinavir & $2(4)$ & 0 & $2(2)$ \\
\hline \multicolumn{4}{|l|}{ PI used at screening } \\
\hline Nelfinavir & $22(42)$ & $21(40)$ & $43(4 I)$ \\
\hline Indinavir & $21(40)$ & $22(42)$ & $43(4 I)$ \\
\hline Saquinavir SGC & $6(12)$ & $6(12)$ & $12(12)$ \\
\hline Amprenavir & $2(4)$ & $2(4)$ & $4(4)$ \\
\hline
\end{tabular}


Table I: Characteristics and disposition of the study patients (intent-to-treat population) (Continued)

\begin{tabular}{|c|c|c|c|}
\hline Ritonavir & $\mathrm{T}(2)$ & $\mathrm{T}(2)$ & $2(2)$ \\
\hline Premature withdrawal from study, n (\%) & $14(27)$ & II (2I) & $25(24)$ \\
\hline Adverse event & $7(13)$ & I (2) & $8(8)$ \\
\hline Consent withdrawn & 0 & $9(17)$ & $9(9)$ \\
\hline Lost to follow-up & $\mathrm{I}(2)$ & I (2) & $2(2)$ \\
\hline Protocol violation & $2(4)$ & 0 & $2(2)$ \\
\hline Protocol-defined virologic failure & $3(6)$ & 0 & $3(3)$ \\
\hline Other & I (2) & 0 & I (I) \\
\hline
\end{tabular}

$*$ Cumulative coronary artery disease risk factors in the abacavir-switch arm: 0 factors $=18$; 1 factor $=16 ; 2$ factors $=12 ; 3$ factors $=5 ; 4$ factors $=$ I. Cumulative coronary artery risk factors in the Pl-continuation arm: 0 factors $=26$; I factor $=12 ; 2$ factors $=13$; and 3 factors $=1$.

Abbreviations: $A I D S=$ acquired immune deficiency syndrome; $A R T=$ antiretroviral therapy; $C D C=$ Centers for Disease Control; $H D L=$ high density lipoprotein; HIV-I = human immunodeficiency virus type I; LDL = low density lipoprotein; LSM = least squares mean; $S D=$ standard deviation; SGC = soft gel capsule.

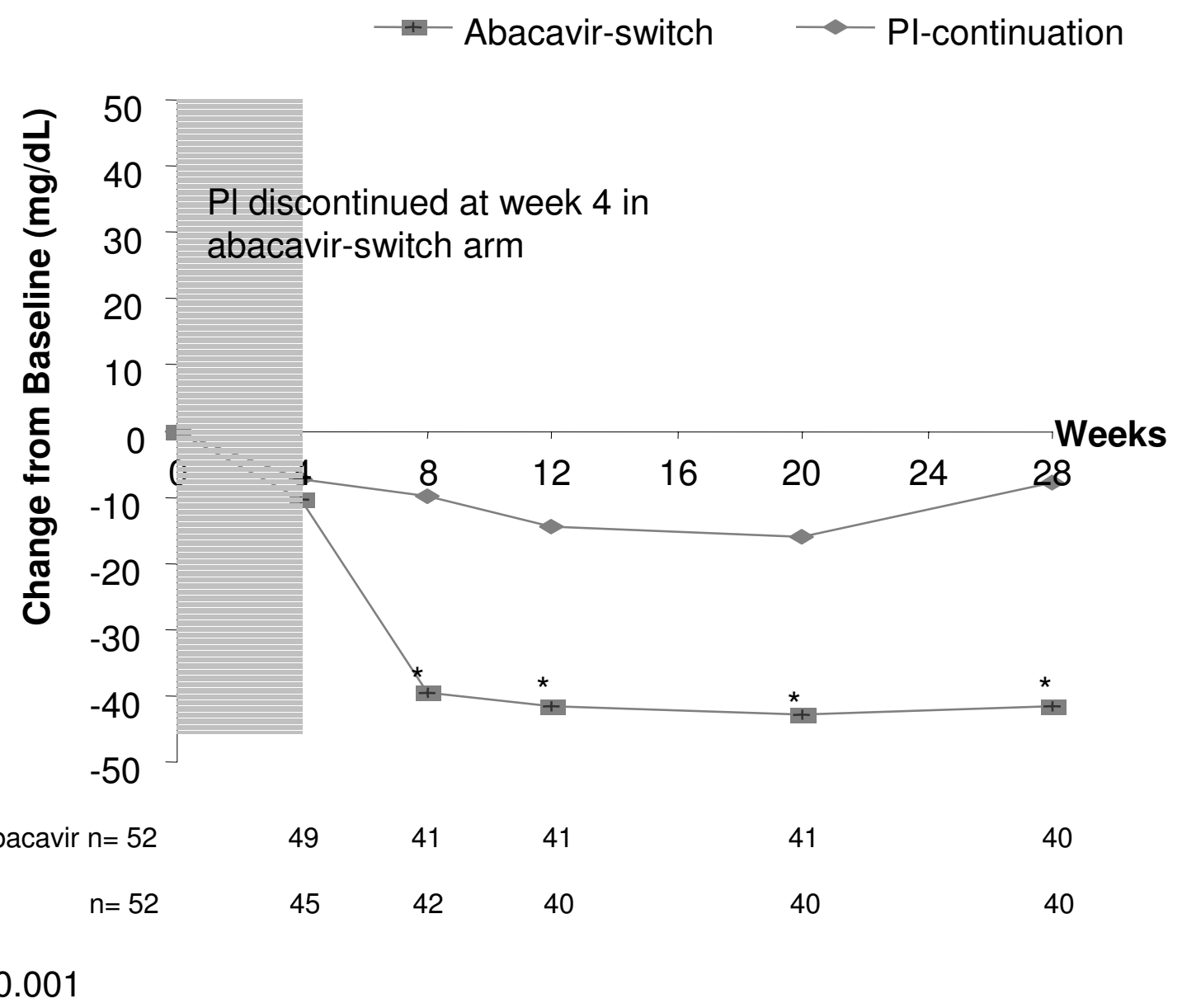

Figure 2

Least squares mean change from baseline in fasting serum total cholesterol. 
$\rightarrow$ Abacavir-switch $\multimap$ PI-continuation

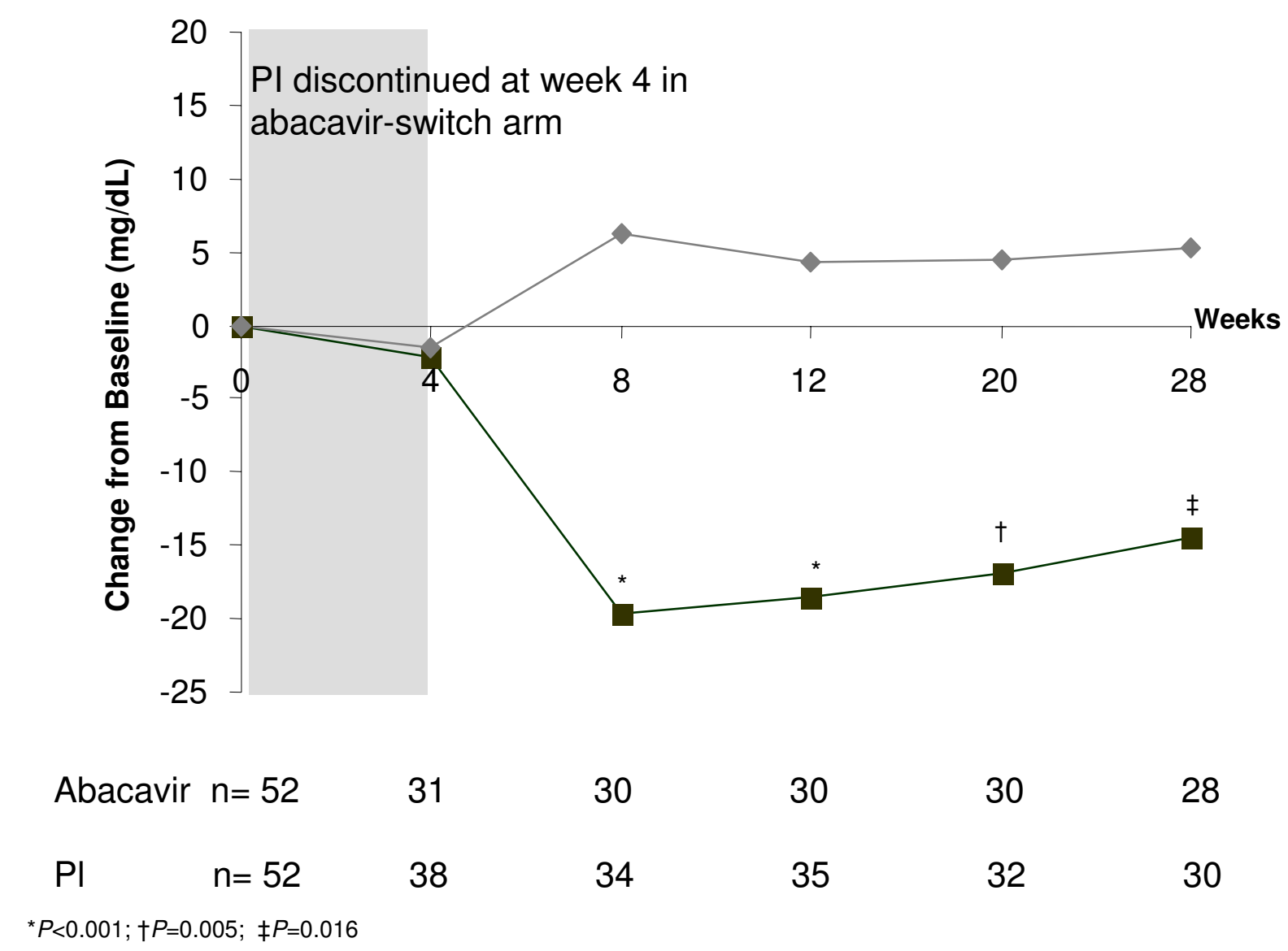

Figure 3

Least squares mean change from baseline in fasting serum LDL-cholesterol.

Changes in serum triglycerides in the two treatment groups paralleled the changes in total cholesterol. At week 28 , the LSM reduction in triglycerides was significantly greater in the abacavir-switch arm than the PI-continuation $\operatorname{arm}(-134$ vs $-36 \mathrm{mg} / \mathrm{dL}, P=0.019)$ (Figure 5$)$. A higher proportion of patients in the abacavir-switch arm had decreases in the triglyceride toxicity grade as compared to the PI-continuation arm, whereas a lower proportion in the abacavir-switch arm had increases in triglyceride toxicity grade (Figure 6).

\section{Efficacy}

In the ITT: $\mathrm{M}=\mathrm{F}$ analysis, no differences were observed between the abacavir-switch and PI-continuation treatment arms at any time during the study regarding proportions of patients achieving undetectable HIV-1 RNA. At week 28 , HIV-1 RNA was $<400$ copies/mL in $69 \%$ [36/52] and $77 \%$ [40/52] of patients in the abacavir-switch and PI-continuation arms, respectively $(P=0.508 ; 95 \%$ CI [$0.25,0.09])$, and $<50$ copies/mL in $62 \%$ [32/52] and $75 \%$ [39/52] of patients in these respective groups $(P=0.206$; $95 \%$ CI $[-0.31,0.04])$.

The ITT: observed analysis showed that HIV-1 RNA remained $<400$ copies $/ \mathrm{mL}$ in $\geq 90 \%$ of patients over the entire study duration. At week 28, the proportion of patients with HIV-1 RNA <400 copies/ml was 90\% [36/ $40]$ and $100 \%$ [40/40] in the abacavir-switch and PI-continuation arms, respectively $(P=0.116 ; 95 \%$ CI $[-0.19$, 0.11]) (Table 2). A significantly higher proportion of patients in the PI-continuation arm achieved HIV-1 RNA 


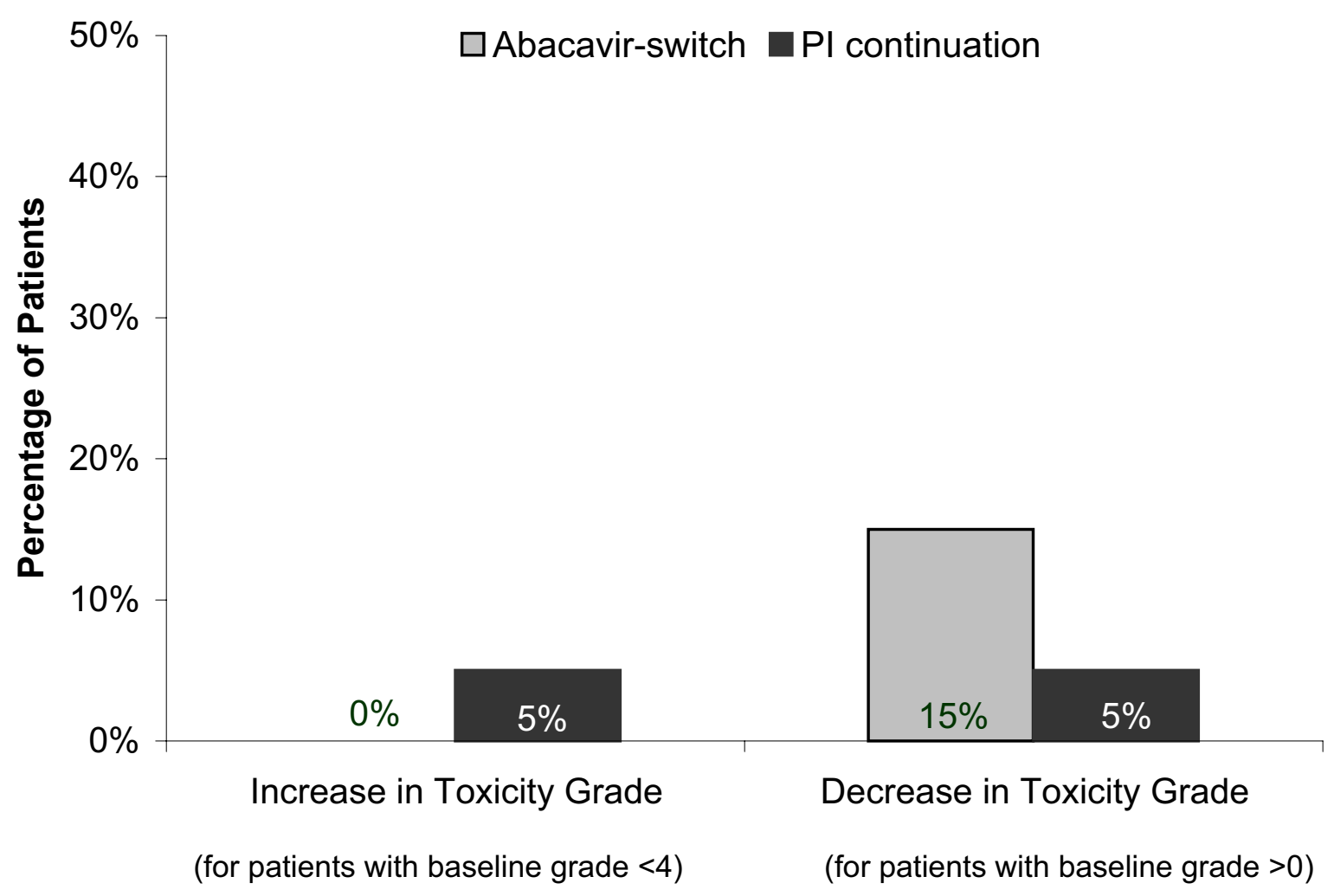

Figure 4

Changes in cholesterol toxicity grade.

levels <50 copies/ml at week 28 (98\% [39/40] vs. 80\% [32/40]; $P=0.029 ; 95 \%$ CI $[-0.31,-0.04])$.

No differences were observed regarding time to virologic breakthrough $(P=0.961)$. Three patients $(6 \%)$ in the abacavir-switch arm were protocol-defined virologic failures. However, one of these patients remained on a 2NRTI/abacavir regimen after withdrawing from the study and his viral load declined. The second of these patients was noncompliant and discontinued his antiretroviral treatment prior to the confirmation blood draw for virologic failure. The third virologic failure in the abacavirswitch arm had a history of prior dual nucleoside therapy for $>1$ year.

At baseline, the mean CD4+ cell counts were 551 and 531 cells $/ \mathrm{mm}^{3}$ in the abacavir-switch and PI-continuation arms, respectively. Changes in $\mathrm{CD} 4+$ counts over the study period were similar. At week 28, the LSM CD4+ cell counts were 514 and 526 cells $/ \mathrm{mm}^{3}$, respectively, with the
LSM difference from baseline being -13 and -1 cells $/ \mathrm{mm}^{3}$, respectively $(P=0.597)$.

\section{Adherence and health outcomes assessments}

PMAQ-7 results showed no apparent differences between the abacavir-switch and PI-continuation arms in overall adherence at week 28 (90\% vs 94\%) or in the Social Support, Adaptability, Knowledge and Attitudes, and Memory and Recall domains. However, the abacavir-switch arm had significantly higher scores in the Scheduling and Timing domain for all study visits ( $P \leq 0.027$ at each week) and in the Physical Effects domain for all visits $(P<0.05)$ except those at weeks 4 and 28. In answer to the PMAQ-7 questions "it is easy for me to take my medicines at the time I am supposed to" and "my medicines are convenient to take", more patients in the abacavir-switch arm answered "definitely true" at week 28 (51\% vs 35\% and $63 \%$ vs $29 \%$, respectively). In the SF-36, the week 28 QOL scores did not differ between treatment arms for most domains, except Vitality (in favor of the PI-continu- 


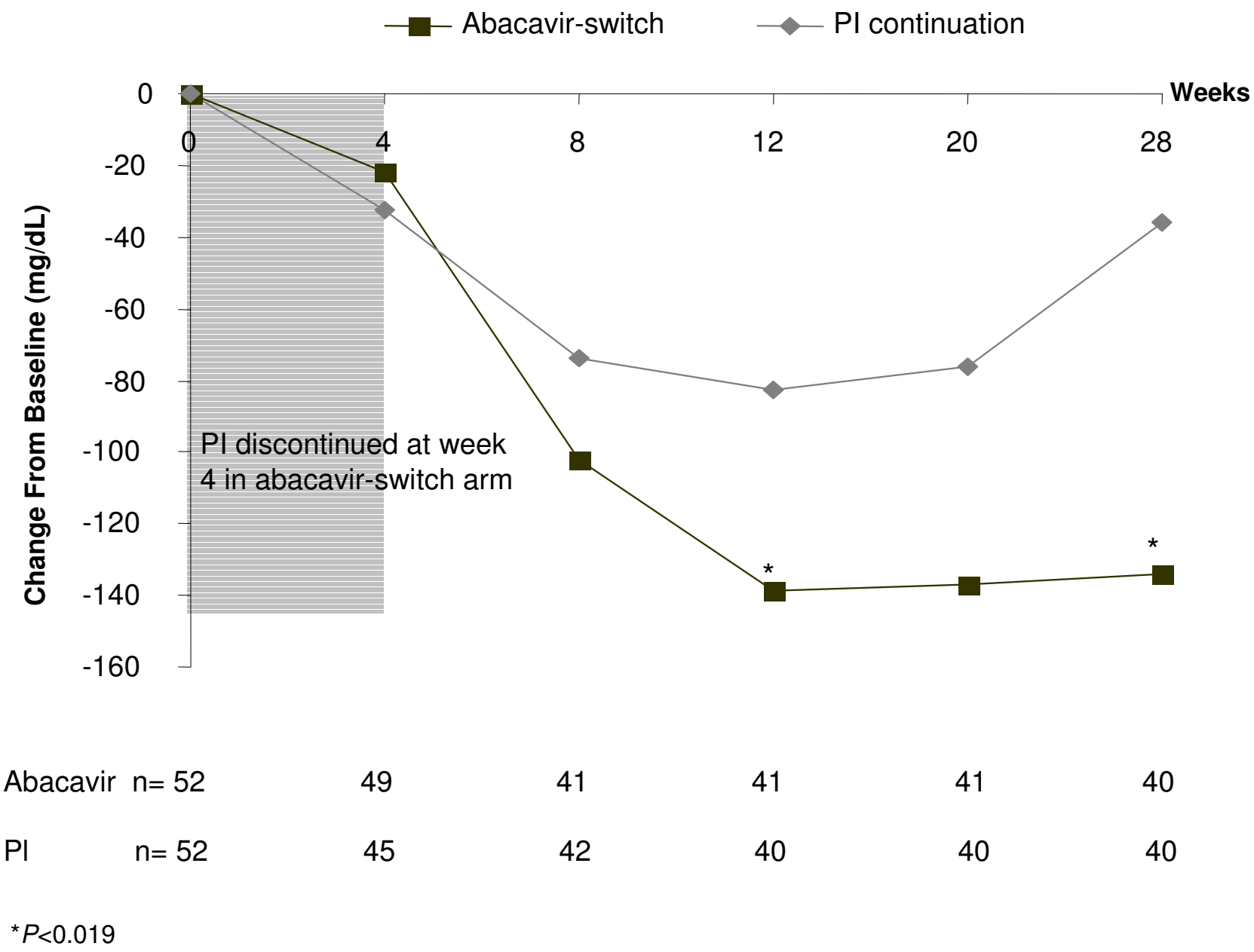

Figure 5

Least squares mean change from baseline in fasting serum triglycerides.

ation arm; $P=0.042$ ) and Health (in favor of the abacavirswitch arm; $P=0.013$ ). There were no differences between treatment arms with respect to any health care utilization parameter.

\section{Safety}

Substitution of PIs with abacavir in HAART regimens was generally well tolerated. No significant differences between treatment arms were observed for cardiovascular, endocrine/metabolic, hepatobiliary tract/pancreatic events, lower respiratory events, musculoskeletal, neurology, psychiatric, or skin adverse events, although more gastrointestinal $(P=0.002)$ and non-site specific adverse events $(P=0.003)$ were observed in the abacavir-switch arm. Treatment-related adverse events reported by $>5 \%$ of patients in the abacavir-switch arm included nausea (12/
$50[14 \%])$, fatigue $(6 / 50[12 \%])$, diarrhea $(4 / 50[8 \%])$, and depressive disorders (3/50 [6\%]). Two patients (4\%) in the abacavir-switch arm experienced possible abacavirrelated hypersensitivity reactions. Adverse events leading to treatment withdrawal in 7 patients in the abacavirswitch arm included possible abacavir-related hypersensitivity reaction (2), mild nausea (2), mild shortness of breath/tachycardia (1), mild disorientation (1), and combination of mild diarrhea, facial edema/numbness and malaise (1). Hyperlipidemia led to treatment withdrawal in 1 patient in the PI-continuation arm. No differences between the two treatments were observed in body weight, waist-to-hip ratio, BMI, lactate, leptin, glucose, insulin, or C-peptide. 


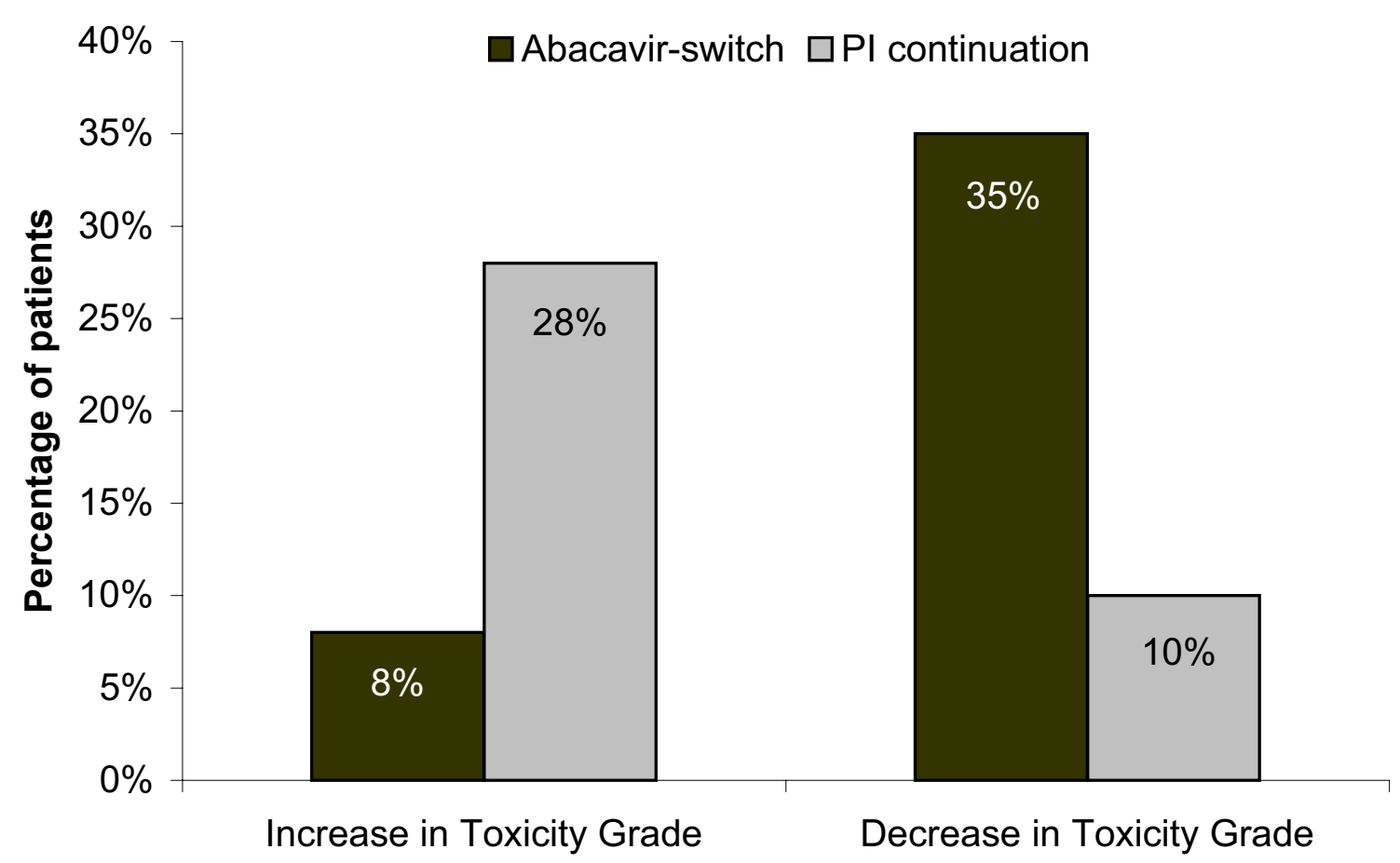

(for patients with baseline grade <4)

(for patients with baseline grade $>0$ )

\section{Figure 6}

Changes in triglycerides toxicity grade.

\section{Discussion}

The results of this study indicate that in hyperlipidemic, virologically suppressed, immunocompetent antiretroviral-experienced patients (HIV-1 RNA <50 copies/mL, CD $4+$ counts $>500$ cells $/ \mathrm{mm}^{3}$ ), substituting abacavir for hyperlipidemia-associated PIs in HAART regimens improves lipid profiles and maintains virologic suppression over a 28-week period. The lipid findings are consistent with those of other studies in which abacavir was substituted for PIs in HAART regimens [28-33]. However, unlike the other studies, ESS40003 evaluated a population consisting entirely of patients who were hyperlipidemic at baseline. Also, unlike two previous studies that reported lipid changes following abacavir substitution [29,30], ESS40003 measured fasting lipids rather than lipids in a non-fasted state (which may confound results). Thus, true differences between abacavir and PI-containing regimens could be determined, and lipid criteria established by the NCEP ATP III could be applied [34]. In addition to monitoring changes in cholesterol and triglycerides, ESS40003 measured changes in other laboratory values known to contribute to atherogenesis (apolipoproteins B and E, LDL subfractions, and indicators of changes in lipid processing [leptin and free fatty acids]) to gain a better understanding of the extent of the improvement in lipid profile following the switch to abacavir. Substitution of hyperlipidemia-associated PIs with abacavir was expected to improve lipid profiles 
Table 2: Proportion of patients with HIV-I RNA $<\mathbf{4 0 0}$ copies $/ \mathrm{mL}$ and $<\mathbf{5 0}$ copies $/ \mathrm{mL}$

\begin{tabular}{|c|c|c|c|c|c|c|c|c|}
\hline \multirow[t]{3}{*}{ Week } & \multicolumn{4}{|c|}{ HIV-I RNA <400 copies/mL, n/N (\%) } & \multicolumn{4}{|c|}{ HIV-I RNA <50 copies/mL, n/N (\%) } \\
\hline & \multicolumn{2}{|c|}{ ITT: Observed } & \multicolumn{2}{|c|}{ ITT: $M=F$} & \multicolumn{2}{|c|}{ ITT: Observed } & \multicolumn{2}{|c|}{ ITT: $M=F$} \\
\hline & Abacavir & $\mathrm{PI}$ & Abacavir & PI & Abacavir & $\mathrm{PI}$ & Abacavir & PI \\
\hline Baseline & $\begin{array}{l}52 / 52 \\
(100)\end{array}$ & $\begin{array}{l}52 / 52 \\
(100)\end{array}$ & $\begin{array}{l}52 / 52 \\
(100)\end{array}$ & $\begin{array}{l}52 / 52 \\
(100)\end{array}$ & $\begin{array}{c}42 / 52 \\
(81)\end{array}$ & $\begin{array}{c}47 / 52 \\
(90)\end{array}$ & $\begin{array}{c}42 / 52 \\
(81)\end{array}$ & $\begin{array}{c}47 / 52 \\
(90)\end{array}$ \\
\hline 4 & $\begin{array}{l}49 / 49 \\
(100)\end{array}$ & $\begin{array}{c}44 / 45 \\
(98)\end{array}$ & $\begin{array}{c}49 / 52 \\
(94)\end{array}$ & $\begin{array}{c}44 / 52 \\
(85)\end{array}$ & $\begin{array}{c}48 / 49 \\
(98)\end{array}$ & $\begin{array}{c}43 / 45 \\
(96)\end{array}$ & $\begin{array}{c}48 / 52 \\
(92)\end{array}$ & $\begin{array}{c}43 / 52 \\
(83)\end{array}$ \\
\hline 8 & $\begin{array}{c}39 / 42 \\
(93)\end{array}$ & $\begin{array}{l}42 / 42 \\
(100)\end{array}$ & $\begin{array}{c}39 / 52 \\
(75)\end{array}$ & $\begin{array}{c}42 / 52 \\
(8 I)\end{array}$ & $\begin{array}{c}38 / 42 \\
(90)\end{array}$ & $\begin{array}{c}40 / 42 \\
(95)\end{array}$ & $\begin{array}{c}38 / 52 \\
(73)\end{array}$ & $\begin{array}{c}40 / 52 \\
(77)\end{array}$ \\
\hline 12 & $\begin{array}{c}38 / 41 \\
(93)\end{array}$ & $\begin{array}{l}40 / 40 \\
(100)\end{array}$ & $\begin{array}{c}38 / 52 \\
(73)\end{array}$ & $\begin{array}{c}40 / 52 \\
(77)\end{array}$ & $\begin{array}{c}38 / 41 \\
(93)\end{array}$ & $\begin{array}{c}39 / 40 \\
(98)\end{array}$ & $\begin{array}{c}38 / 52 \\
(73)\end{array}$ & $\begin{array}{c}39 / 52 \\
(75)\end{array}$ \\
\hline 20 & $\begin{array}{c}38 / 41 \\
(93)\end{array}$ & $\begin{array}{l}40 / 40 \\
(100)\end{array}$ & $\begin{array}{c}38 / 52 \\
(73)\end{array}$ & $\begin{array}{c}40 / 52 \\
(77)\end{array}$ & $\begin{array}{c}32 / 41 \\
(78)\end{array}$ & $\begin{array}{c}38 / 40 \\
(95)\end{array}$ & $\begin{array}{c}32 / 52 \\
(62)\end{array}$ & $\begin{array}{c}38 / 52 \\
(73)\end{array}$ \\
\hline 28 & $\begin{array}{c}36 / 40 \\
(90)\end{array}$ & $\begin{array}{l}40 / 40 \\
(100)\end{array}$ & $\begin{array}{c}36 / 52 \\
(69)\end{array}$ & $\begin{array}{c}40 / 52 \\
(77)\end{array}$ & $\begin{array}{c}32 / 40 \\
(80)\end{array}$ & $\begin{array}{c}39 / 40 \\
(98)\end{array}$ & $\begin{array}{c}32 / 52 \\
(62)\end{array}$ & $\begin{array}{c}39 / 52 \\
(75)\end{array}$ \\
\hline
\end{tabular}

Abbreviations: ITT = intent to treat; $\mathrm{M}=\mathrm{F}=$ missing equals failure analysis; $\mathrm{PI}=$ protease inhibitor.

because results of direct comparisons of abacavir/NRTI regimens with PI/NRTI regimens (same NRTIs administered) in antiretroviral-naïve patients have shown no significant effects on lipids with abacavir/NRTI-containing regimens [18-20].

Cross-trial comparisons with other abacavir-switch studies regarding lipid changes are limited by differences between studies in prevalence and severity of hyperlipidemia prior to the switch, specific PIs administered, pre-existing CAD risk factors of the particular patients enrolled, and stipulated dietary and exercise restrictions. Nevertheless, some generalizations can be made between the lipid changes noted in ESS40003 and those reported in other abacavir-switch studies [28-33]. First, as in these other studies, decreases in total cholesterol, LDL-cholesterol, and triglycerides occurred rapidly following the switch to abacavir, with statistically significant differences noted between treatment arms within 4 weeks. Second, as would be expected, the magnitude of the reduction in total- and LDL-cholesterol and triglycerides at week 28 in our study was markedly greater than that reported in studies that included normolipidemic as well as hyperlipidemic patients. Third, as in the other studies, switching from a PI to abacavir had no significant effect on HDL-cholesterol.

The small reduction in lipids observed in the PI-continuation arm may have occurred because patients were aware that their lipids were being monitored, and therefore may have exerted more self-control than usual regarding their dietary fat intake and frequency of smoking, or may have exercised more (not monitored in this study). A similar phenomenon was observed over 48 weeks in another PIto-abacavir switch study, CNA30017 [29]. As no change in body weight, BMI, or waist-to-hip ratio was observed in our study in either group, anthropomorphic parameters were unlikely to have accounted for the decreases in lipids observed during this study. The 28-week duration of this study may have been too short to see significant changes in BMI or waist-to-hip ratios. However, in the Swiss HIV Cohort Study, substitution of abacavir for a PI was not associated with a change in waist-to-hip ratios even after 48 weeks post-switch [30].

Maintenance of virologic suppression and increases in CD4+ cell count over the 24-week period following the switch to abacavir were expected in view of the lack of change in these surrogate markers previously observed in abacavir-switch studies conducted over 48 weeks to 1 year $[27,29]$.

The abacavir-containing regimen was generally well-tolerated, and the type and incidence of adverse events (notably fatigue and nausea) and rare occurrence of suspected abacavir-related hypersensitivity reactions were consistent with what has been reported in other clinical trials [16]. New adverse events in the PI-continuation arm were not expected as patients had been stabilized on this treatment for $>3$ months. This fact may have accounted for the comparatively lower incidence of GI adverse events in the PIcontinuation arm than in the abacavir-switch arm, a finding that has not been observed in direct comparisons of abacavir with PIs (indinavir or nelfinavir) administered with the same background antiretroviral drugs $[18,19,21]$. 
Results of the PMAQ-7 indicated significantly better Scheduling and Timing scores in the abacavir-switch arm. Significant improvement in this PMAQ-7 dimension was similarly reported at 24 weeks in the PI-to-abacavir switch study, COL30305 [33]. Improved scores in this dimension may have been related to the simpler, twice-daily dosing of abacavir compared to the patients' previous PIcontaining regimens. The proportion of patients reporting $100 \%$ adherence previously was shown to be higher at 24 weeks in one PI-to-abacavir switch study (COL30305; $92 \%$ vs 68\%) [33] and at 48 weeks in another (CNA30017; 91\% vs 76\%) [29]. In these trials, better adherence with the abacavir-containing regimen was believed to be due at least in part to the relatively lower pill count and absence of special dosing requirements incurred by abacavir-containing HAART. The absence of a significant difference in overall QOL between the abacavir-switch and PI-continuation arms was not unexpected in view of the same finding being demonstrated on the SF-36 at 24 weeks in COL30305 [33].

Switching to abacavir is just one of several switch strategies that have been investigated to date in an attempt to remedy hyperlipidemia in patients receiving PI-containing HAART. It is acknowledged that the ideal candidate for this switch strategy is a patient started on triple therapy, where pre-existing abacavir resistance is unlikely [30,32]. Another switch strategy-replacement of hyperlipidemiaassociated PIs with PIs that have a low likelihood of causing significant lipid elevation or adversely affecting the total cholesterol:HDL cholesterol ratio (fosamprenavir or atazanavir)-would be expected to improve lipid profiles in HIV-infected patients [6-8,35]. Attempts to reduce lipids by switching from a hyperlipidemia-associated PI to NNRTIs have also been investigated [32,36-43]. More favorable lipid effects appear to occur when a switch is made to nevirapine than to efavirenz $[42,43]$.

This study had several limitations. As patients in this study had mean CD4+ cell counts $>500$ cells $/ \mathrm{mm}^{3}$, they were highly immunocompetent and may not be representative of typical HIV-infected patients presenting to their physician with PI-associated hyperlipidemia. The study did not evaluate the influence of NRTI background drugs on lipid changes because the patients remained on the same baseline NRTIs. This could have affected the results because stavudine is known to elevate cholesterol and triglyceride levels [44], whereas zidovudine and lamivudine do not. Most studies have found that switching therapy tends to be optimally effective in patients whose viral load is fully suppressed for at least 6 months rather than the 3 months in our study [45]. This shorter pre-study time of viral suppression could have biased the virologic results against abacavir, as could allowing prior suboptimal nucleoside therapy. As we did not have information about prior NRTI combinations that many patients received pre-study, we could not assess whether these earlier NRTI combination regimens had been inadequate. Lipid data for study participants prior to their receipt of PI-containing regimens were not available to the investigators; thus, whether PIs were the cause of the patients' hyperlipidemia could not be verified. Dietary intake and physical activity assessments were not performed in this study to evaluate whether either differed between the treatment arms.

Further valuable clinical information could have been acquired from this study had switch agents in addition to abacavir been used as comparators. In the only study of this type that has been conducted to date - the Nevirapine-Efavirenz-Abacavir (NEFA) Study - a significantly lower proportion of stabilized HAART recipients (HIV-1 RNA $<50$ copies $/ \mathrm{mL}$ for $=6$ months) switching from a PI to abacavir developed fasting plasma triglycerides $>400$ $\mathrm{mg} / \mathrm{dL}$ and plasma cholesterol $>240 \mathrm{mg} / \mathrm{dL}$ at 12 months compared to treatment groups in which patients switched from a PI to efavirenz or nevirapine [32]. Kaplan-Meier estimates of the likelihood of reaching the primary treatment end point (increase in HIV-1 RNA levels to $\geq 200$ copies/mL, progression to AIDS, or death) in NEFA showed no significant differences between treatments. Median CD4+ cell counts increased above baseline similarly in all three treatment arms (by $39-50$ cells $/ \mathrm{mm}^{3}$ at 12 months). However, the abacavir-switch arm had a significantly lower incidence of adverse events than the efavirenz-switch and nevirapine-switch arms (41\% vs $57 \%$ and $54 \%, P=0.03$ ), a lower incidence of neuropsychiatric adverse events than the efavirenz group ( $9 \%$ vs $31 \%$; Grade 3 or $4: 0.7 \%$ vs $14 \%$ ), and significantly fewer cases of discontinuation of study drug due to adverse events ( $6 \%$ vs $17 \%$ and $17 \%, P=0.01$ ). Overall, NEFA, like our study, indicated that abacavir was an appropriate drug to substitute for PIs in HAART regimens as long as patients were virologically suppressed pre-switch and minimally antiretroviral-experienced. Our study differed from NEFA in that all participants in ESS40003 had PI-associated hyperlipidemia at baseline (NEFA included only 7-13\% with triglycerides $>400 \mathrm{mg} / \mathrm{dL}$ and $21-25 \%$ with total cholesterol $>240 \mathrm{mg} / \mathrm{dL}$ ) and because our study used a less stringent definition of virologic failure (HIV-1 RNA $>1000$ copies/mL on two occasions at least 1 week apart vs. HIV-1 RNA $\geq 200$ copies $/ \mathrm{mL}$ at $\geq 16$ weeks, with subsequent confirmation [NEFA]).

\section{Conclusions}

In conclusion, in antiretroviral-experienced patients with HIV-1 RNA $<50$ copies/mL and CD4+ counts $>500$ cells/ $\mathrm{mm}^{3}$, substituting abacavir for hyperlipidemia-associated PIs in HAART regimens improves lipid profiles and maintains virologic suppression over a 28 -week period, and it simplifies treatment. 


\section{Competing interests}

The author(s) declare that they have no competing interests.

\section{Authors' contributions}

JEH, PHK and VCW conceived the study design, PHK, MGS, EDJ, AR, JFO, VCW, JWS reviewed and approved study design, VCW provided the statistical methods for the study and performed the statistical analysis of the results, EH, VCW, JHW, JWS wrote, reviewed and edited the protocol, GEP drafted manuscript and evaluated lipid data previously published in antiretroviral studies described in Background and Discussion, JWF, JEH, PHK, MGS, EDJ, AR, JFO, JEH, JWF, JHW, JWS, ADS-C, VCW reviewed and edited the manuscript, ADS-C, JWF, PHK, MGS, EDJ, AR, JFO enrolled study subjects, ADS-C, JWF, JEH, JHW monitored the study, ADS-C, JWF, JEH, JWS, VCW evaluated the clinical data from the study, ADS-C set up the study at study sites and JEH contributed to secure funding.

\section{Acknowledgements}

The authors wish to thank the study participants, the clinical investigators and their respective staff members, and the GlaxoSmithKline ESS40003 study team: Heath Hair, Ilisse Minto, J. Phillips, Janice Myers, and Teresa Kauf. The results of this study were presented in part in Poster WePeC6267 at the XIVth International AIDS Conference, Barcelona, Spain, July 7-12, 2002.

\section{References}

I. Palella FJ Jr, Delaney KM, Moorman AC, Loveless MO, Fuhrer J, Satten GA, Aschman DJ, Holmberg SD: Declining morbidity and mortality among patients with advanced human immunodeficiency virus infection. $N$ Engl J Med 1998, 338:853-860.

2. Hogg RS, Yip B, Kully C, Craib KJ, O'Shaughnessy MV, Schechter MT, Montaner JS: Improved survival among HIV-infected patients after initiation of triple-drug antiretroviral regimens. CMAJ 1999, 160:659-665.

3. Jordan J, Carranza Rosenzweig J, Pathak D, Pilon T: Perceived influence of regimen characteristics on adherence. 5th International Congress on Drug Therapy in HIV Infection. Glasgow, United Kingdom Abstract/Poster 121: October 22-26, 2000

4. Currier JS: Cardiovascular risk associated with HIV therapy. J Acquir Immune Defic Syndr 2002, 3 I (suppI I):S16-S23.

5. Periard D, Telenti A, Sudre P, Cheseaux JJ, Halfon P, Reymond MJ, Marcovina SM, Glauser MP, Nicod P, Darioli R, Mooser V: Atherogenic dyslipidemia in HIV-infected individuals treated with protease inhibitors. The Swiss HIV Cohort Study. Circulation 1999, 100:700-705.

6. Piliero PJ, Cahn P, Pantaleo G, Gatell J, Squires K, Percival L, Sanne I, Wood R, Phanuphak P, Shelton S, Lazzarin A, Thiry A, Kelleher T, Giordano M, Schnittman SM: Atazanavir: a once-daily protease inhibitor with a superior lipid profile - results of clinical trials at week 48. 9th Conference on Retroviruses and Opportunistic Infections. Seattle, Washington Abstract/poster 706T:. February 24-28, 2002

7. Rodriguez-French A, Boghossian J, Gray GE, Nadler JP, Quinones AR, Sepulveda GE, Millard JM, Wannamaker PG: The NEAT study: a 48-week study to compare the antiviral efficacy and safety of GW433908 versus nelfinavir in antiretroviral therapy-naïve HIV-I-infected patients. J Acquir Immune Defic Syndr 2004, 35:22-32.

8. Horban A, Staszewski S, Walmsley S, Pierone G, Sexton A, Stark T: Favourable increases in high-density lipoprotein cholesterol (HDL-C) concentrations in chronic HIV-infected therapynaïve subjects receiving $908 / \mathrm{r}$ in the SOLO study
(APV30002). 9th European AIDS Conference. Warsaw, Poland Abstract/slide presentation F 8/3:. October 25-29, 2003

9. Grunfeld C, Pang M, Doerrler W, Shigenaga JK, Jensen P, Feingold KR: Lipids, lipoproteins, triglyceride clearance, and cytokines in human immunodeficiency virus infection and the acquired immunodeficiency syndrome. J Clin Endocrinol Metab 1992, 74: $1045-1052$.

10. Petit JM, Duong M, Duvillard L, Florentin E, Portier H, Lizard G, Brun JM, Gambert P, Verges B: LDL-receptors expression in HIVinfected patients: relations to antiretroviral therapy, hormonal status, and presence of lipodystrophy. Eur J Clin Invest 2002, 32:354-359.

II. Riddle TM, Kuhel DG, Woolett LA, Fichtenbaum C, Hui DY: HIV protease inhibitor induces fatty acid and sterol biosynthesis in liver and adipose tissues due to the accumulation of activated sterol regulatory element-binding proteins in the nucleus. J Biol Chem 200I, 276:375 I4-375 I9.

12. Sekhar RV, Jahoor F, White AC, Pownall HJ, Visnegarwala F, Rodriguez-Barradas MC, Sharma M, Reeds PJ, Balasubramanyam A: Metabolic basis of HIV-lipodystrophy syndrome. Am J PhysiolEndocrinol Metab 2002, 283:E332-E337.

13. Klein D, Hurley LB, Quesenberry CP Jr, Sidney S: Do protease inhibitors increase the risk for coronary heart disease in patients with HIV-I infection. J Acquir Immune Defic Syndr 2002, 30:47I-477.

14. Holmberg S, Moorman A, Tong T, Ward D, Wood K, Greenberg AE, Janssen RS, for the HIV Outpatient Study (HOPS) Investigators: Protease inhibitor use and adverse cardiovascular outcomes in ambulatory HIV patients. 9th Conference on Retroviruses and Opportunistic Infections. Seattle, Washington Abstract 698T:. February 24-28, 2002

15. Bozzette SA, Ake CF, Tam HK, Chang SW, Louis TA: Cardiovascular and cerebrovascular events in patients treated for human immunodeficiency virus infection. New Engl I Med 2003, 348:702-7I0.

16. Hervey PS, Perry CM: Abacavir - a review of its clinical potential in patients with HIV infection. Drugs 2000, 60:447-479.

17. Murphy RL, Smith W]: Switch studies: a review. HIV Med 2002, 3:146-155.

18. Vibhagool A, Cahn P, Schlechter M, Smaill F, Soto-Ramirez L, Carosi G, Montroni M, Pharo CE, Jordan JC, Thomas NE, Pearce G: Triple nucleoside treatment with abacavir plus the lamivudine/ zidovudine combination tablet (COM) compared to indinavir/COM in antiretroviral therapy-naïve adults: results of a 48-week open label, equivalence trial (CNA30I4). Curr Med Res Opin 2004, 20: II03-III4.

19. Matheron S, Descamps D, Boué F, Livrozet J-M, Lafeuillade A, Aquilina C, Troisvallets D, Goetschel A, Brun-Vezinet F, Mamet J-P, Thiaux C, on behalf of CNAF3007 Study Group: Triple nucleoside combination zidovudine/lamivudine/abacavir versus zidovudine/lamivudine/nelfinavir as first-line therapy in HIV-I-infected adults: a randomized trial. Antivir Ther 2003, 8:163-171.

20. Kumar P, Rodriguez-French A, Thompson M, Tashima K, Wannamaker P, Williams V, Pappa K: Prospective study of hyperlipidemia in ART-naïve subjects taking Trizivir (TZV), Combivir (COM)/nelfinavir (NFV), or stavudine (d4T)/lamivudine (3TC)/NFV. 2nd IAS Conference on HIV Pathogenesis and Treatment. Paris, France Abstract/Poster 709:. July 13-16, 2003

21. Staszewski S, Keiser P, Montaner J, Raffi F, Gathe J, Brotas V, Hicks C Hammer SM, Cooper D, Johnson M, Tortell S, Cutrell A, Thorborn D, Isaacs R, Hetherington S, Steel H, Spreen W, for the CNAAB3005 International Study Team: Abacavir-lamivudine-zidovudine vs indinavir-lamivudine-zidovudine in antiretroviral-naïve HIVinfected adults: a randomized equivalence trial. JAMA 200I, 285: II55-II63

22. Friedewald WT, Levy RI, Fredrickson DS: Estimation of the concentration of low-density lipoprotein cholesterol in plasma, without use of the preparative ultra centrifuge. Clin Chem 1972, 18:499-502.

23. Nauck M, Warnick GR, Rifai N: Methods for measurement of LDL-cholesterol: a critical assessment of direct measurement by homogeneous assays versus calculation. Clin Chem 2002, 48:236-254.

24. Hetherington S, McGuirk S, Powell G, Cutrell A, Naderer O, Spreen $B:$ Hypersensitivity reactions during therapy with the nucle- 
oside reverse transcriptase inhibitor abacavir. Clin Ther 200I, 23:1603-16|4.

25. Hewitt RG: Abacavir hypersensitivity reaction. Clin Infect Dis 2002, 34: | |37- I| 42

26. Childress JK, Jhingran P, Scott-Lennox J, Tolson J: Development and initial evaluation of the Patient Medication Adherence Questionnaire (PMAQ). 6th European Conference on Clinical Aspects and Treatment of HIV Infection. Hamburg, Germany Abstract/poster N-23:. October II-I5, I 997

27. Ware JE Jr, Snow KK, Kosinski M, Gandek B: SF-36 Health Survey manual and interpretation guide. Boston, Mass: Nimrod Press; 1993.

28. Katlama C, Fenske S, Gazzard B, Lazzarin A, Clumeck N, Mallolas J, Lafeuillade A, Mamet J-P, Beauvais L, on behalf of the AZL30002 European Study Team: TRIZAL study: switching from successful HAART to Trizivir ${ }^{\text {TM }}$ (abacavir-lamivudine-zidovudine combination tablet): 48 weeks efficacy, safety and adherence results. HIV Med 2003, 4:79-86.

29. Clumeck N, Goebel F, Rozenbaum W, Gerstoft J, Staszewski S, Montaner J, Johnson M, Gazzard B, Stone C, Athisegaran R, Moore S, on behalf of the CNA300I7 Study Team: Simplification with abacavir-based triple nucleoside therapy versus continued protease inhibitor-based highly active antiretroviral therapy in HIV-I-infected patients with undetectable plasma HIV-I RNA. AIDS 200I, 15:1517-1526.

30. Opravil M, Hirschel B, Lazzarin A, Furrer H, Chave J-P, Yerly S, Bisset LR, Fischer M, Vernazza P, Bernasconi E, Battegay M, Ledergerber B, Günthard H, Howe C, Weber R, Perrin L, for the Swiss HIV Cohort Study: A randomized trial of simplified maintenance therapy with abacavir, lamivudine, and zidovudine in human immunodeficiency virus infection. I Infect Dis 2002, 185: I 25 I- / 260.

31. Moyle G], Baldwin C, Langroudi B, Mandalia S, Gazzard BG: A 48week, randomized, open-label comparison of three abacavirbased substitution approaches in the management of dyslipidemia and peripheral lipoatrophy. J Acquir Immune Defic Syndr 2003, 33:22-28.

32. Martínez E, Arnaiz JA, Podzamczer D, Dalmau D, Ribera E, Domingo P, Knobel H, Riera M, Pedrol E, Force L, Llibre JM, Segura F, Richart C. Cortés C, Javaloyas M, Aranda M, Cruceta A de Lazzari E, Gatell JM, for the Nevirapine, Efavirenz, and Abacavir (NEFA) Study Team: Substitution of nevirapine, efavirenz, or abacavir for protease inhibitors in patients with human immunodeficiency virus infection. N Engl J Med 2003, 349: 1036-1046.

33. Pulvirenti J, Goodwin D, Slater L, Rodriguez A, Fleming J, Williams V, Kauf T, Hernandez I: Simplification of protease inhibitor (PI)containing HAART regimens with abacavir $(A B C)$ maintains viral suppression and favorable adherence in HIV-I infected adults (COL30305). 39th Annual Meeting of the Infectious Diseases Society of America. San Francisco, California Abstract/poster 689:. October 25-28, 200 I

34. National Cholesterol Education Program: Detection, Evaluation, and Treatment of High Blood Cholesterol in Adults (Adult Treatment Panel III). National Heart, Lung, and Blood Institute, National Institutes of Health, Bethesda, Maryland. NIH Publication No. 0 I36702001 .

35. Markowitz M, Simon V, Vasan S, Louie M, Hurley A, Rowe L, Hogan $C:$ 48-Week results of an atazanavir-based $Q D$ regimen in patients switching from BID PI-based HAART. 2nd International AIDS Society (IAS) Conference on HIV Pathogenesis and Treatment. Paris, France Abstract/poster 543:. July 13-16, 2003

36. Bonnet E, Lepec R, Bluteau M, Herve R, Bernard J, Perret B, Izopet J, Massip P: Evolution of lipodystrophy syndrome and lipidic profile in HIV patients after switching from protease inhibitors to efavirenz. 7th Conference on Retroviruses and Opportunistic Infections. San Francisco, California Abstract 49:. January 30-February 2, 2000

37. Estrada V, de Villar NGP, Larrad MTM, Lopez AG, Fernandez C, Serrano-Rios M: Long-term metabolic consequences of switching from protease inhibitors to efavirenz in therapy for human immunodeficiency virus-infected patients with lipoatrophy. Clin Infect Dis 2002, 35:69-76.

38. Negredo E, Ribalta J, Paredes R, Ferré R, Sirera G, Ruiz L, Salazar J Reiss P, Masana L, Clotet B: Reversal of atherogenic lipoprotein profile in HIV-I infected patients with lipodystrophy after replacing protease inhibitors by nevirapine. AIDS 2002 16:1383-1389.
39. Martínez E, Conget I, Lozano L, Casamitjana R, Gatell JM: Reversion of metabolic abnormalities after switching from HIV-I protease inhibitors to nevirapine. AIDS 1999, 13:805-810.

40. Barreiro P, Soriano V, Blanco F, Casimiro C, de la Cruz IJ, GonzalezLahoz J: Risks and benefits of replacing protease inhibitors by nevirapine in HIV-infected subjects under long-term successful triple combination therapy. AIDS 2000, I 4:807-8I 2.

4I. Clotet B, van der Valk M, Negredo E, Reiss P: Impact of nevirapine on lipid metabolism. J Acquir Immune Defic Syndr 2003, 34:S79-S84

42. Fontas E, van Leth F, Sabin CA, Friis-Møller N, Rickenbach M, Monforte D, Kirk O, Dupon M, Morfeldt L, Mateu S, Petoumenos K, ElSadr W, de Wit S, Lundgren JD, Pradier C, Reiss P, for the D:A:D Study Group: Lipid profiles in HIV-infected patients receiving combination antiretroviral drugs associated with different lipid profiles? J Infect Dis 2004, I 89: I 056- 1074.

43. Bucher HC, Kofler A, Nuesch R, Young J, Battegay M, Opravil M: Meta-analysis of randomized controlled trials of simplified versus continued protease inhibitor-based antiretroviral therapy in HIV-I-infected patients. AIDS 2003, 17:245I-2459.

44. Gallant J, Staszewski AS, Pozniak A, Lu B, Miller MD, Coakley DF, Cheng A: Favorable lipid and mitochondrial (mt) DNA profile for tenofovir disoproxil fumarate (TDF) compared to stavudine (d4T) in combination with lamivudine (3TC) and efavirenz (EFV) in antiretroviral therapy (ART) naïve patients: a 48-week interim analysis. 42nd Interscience Conference on Antimicrobial Agents and Chemotherapy. San Diego, California Abstract LB-2: September 27-30, 2002

45. Dreschler H, Powderly WG: Switching effective antiretroviral therapy: a review. Clin Infect Dis 2002, 35:1219-1230.

\section{Pre-publication history}

The pre-publication history for this paper can be accessed here:

http://www.biomedcentral.com/1471-2334/5/2/prepub

Publish with BioMed Central and every scientist can read your work free of charge

"BioMed Central will be the most significant development for disseminating the results of biomedical research in our lifetime. "

Sir Paul Nurse, Cancer Research UK

Your research papers will be:

- available free of charge to the entire biomedical community

- peer reviewed and published immediately upon acceptance

- cited in PubMed and archived on PubMed Central

- yours - you keep the copyright 